\title{
Relationship between the expression of CD133, HIF-1 $\alpha$, VEGF and the proliferation and apoptosis in hypoxic human prostate cancer cells
}

\author{
LINGYUN LIU, ZUOWEN LIANG, KAIMIN GUO and HONGLIANG WANG \\ Department of Andrology, The First Hospital of Jilin University, Changchun, Jilin 130021, P.R. China
}

Received March 31, 2017; Accepted August 1, 2017

DOI: $10.3892 / 01.2017 .6726$

\begin{abstract}
This study measured the levels of expression of CD133, hypoxia-inducible factor (HIF)- $1 \alpha$ and vascular endothelial growth factor (VEGF) in human prostate cancer cells grown under hypoxic and non-hypoxic conditions to compare the values to resulting amounts of proliferation and apoptosis in the cells. Human prostate cancer cell line LNCaP cells were routinely thawed, cultured and passaged. Actively growing cells were divided into batches. Cells in the control group were grown under $5 \% \mathrm{CO}_{2}+20 \% \mathrm{O}_{2}$, and those in the hypoxia group were grown under $5 \% \mathrm{CO}_{2}+1 \%$ $\mathrm{O}_{2}$. The experiments were performed after 12,24 and $72 \mathrm{~h}$ under each growth condition. The percentages of $\mathrm{CD}^{2} 3^{+}$cells were detected by flow cytometry, the expression of HIF-1 $\alpha$ and VEGF was detected by western blot analysis, the cell proliferation rate was detected by the MTT assay, and the apoptotic rate was detected by flow cytometry. The results showed that the percentage of $\mathrm{CD}_{133^{+}}$cells, and the expressions of HIF-1 $\alpha$ and VEGF for the cells in the hypoxia group increased gradually from 12 to 24 , to $72 \mathrm{~h}$, while there were no equivalent changes in the control group. Cell proliferation in the two groups increased gradually from 12 to 24 , to $72 \mathrm{~h}$, but was significantly higher at all time-points in the hypoxia group $(\mathrm{p}<0.05)$. There was no significant difference in terms of the amount of apoptotic cells at any of the three different time-points in either group, but the apoptotic cells in the hypoxia group were significantly less than those in the control group at each time-point, and the difference was statistically significant $(p<0.05)$. We conclude that the expression of $\mathrm{CD} 133^{+}, \mathrm{HIF}-1 \alpha$ and VEGF in human prostate cancer cells is related to conditions of hypoxia, which ultimately promotes the proliferation and reduces apoptosis in these cells.
\end{abstract}

Correspondence to: Dr Hongliang Wang, Department of Andrology, The First Hospital of Jilin University, 71 Xinmin Street, Changchun, Jilin 130021, P.R. China

E-mail:1lygkm@163.com

Key words: prostate cancer cells, hypoxia, $\mathrm{CD} 133^{+}$cells, hypoxia-inducible factor, vascular endothelial growth factor, proliferation, apoptosis

\section{Introduction}

The incidence of prostate cancer occupies the first place among male malignant tumors, and its mortality rate ranks 2 nd in Europe and the United States. In China, the disease ranks 5th among cancers in males (1). The main prostate cancer therapies include surgical resection combined with radiotherapy and chemotherapy, but $20-40 \%$ of patients exhibit resistance to the radiotherapy and/or chemotherapy (2). Approximately $10-50 \%$ of the mass of the tumors is composed of hypoxic cells lacking oxygen-free radicals that can induce DNA damage to destroy the tumorigenic cells (3). The expression of hypoxia-inducible factor-1 (HIF-1) can be induced under hypoxic conditions in tumor cells. HIF-1 $\alpha$ is a nuclear protein with transcriptional activity modulating oxygen homeostasis in tissues. After binding to its target gene, it regulates the adaptive response of cells to hypoxia-ischemia and is involved in cell proliferation, energy metabolism, vascular endothelial growth factor (VEGF) production (4), epithelialmesenchymal transition, tumor invasion and metastasis, and resistance to radiotherapy and chemotherapy (5). Tumor stem cells (CSCs) have been described in lung, breast, colorectal cancer and other tumor tissues (6) where they promote tumor proliferation, differentiation, apoptosis and autophagy (7). CD133 is a commonly used CSC marker, CD133+ cells express an ATP-binding drug transporter that can affect the sensitivity of tumor cells to radiotherapy and chemotherapy (8).

Based on this, the aim of the present study was to analyze the relationship between the expression of CD133+, HIF-1 $\alpha$, VEGF and the proliferation or apoptosis of prostate cancer cells to expand the repertoire of possible targets for improving the radio/chemosensitivity of tumor cells.

\section{Materials and methods}

Materials. The human prostate $\mathrm{LNCaP}$ cancer cell line was purchased from the Cell Resource Center of the Shanghai Sangon Biological Engineering Technology and Service Co. (Shanghai, China), RPMI-1640 medium and trypsin were both purchased from Gibco (Carlsbad, CA, USA), neonatal calf serum was purchased from Hyclone (Logan, UT, USA), the cell culture incubator was purchased from Thermo Fisher Scientific, Inc. (Waltham, MA, USA). 
LNCaP cells were routinely thawed, cultured and passaged. For experiments the cells were divided into two batches, cells in the control group were grown in a $5 \% \mathrm{CO}_{2}+20 \% \mathrm{O}_{2}$ environment and cells in the hypoxia group in a $5 \% \mathrm{CO}_{2}+1 \% \mathrm{O}_{2}$ environment. All the cells were cultured at $37^{\circ} \mathrm{C}$ with saturated humidity. RPMI-1640 containing $10 \%$ neonatal calf serum, 100 $\mathrm{U} / \mathrm{ml}$ of penicillin and $100 \mu \mathrm{g} / \mathrm{ml}$ of streptomycin were used as culture media. The cells grew adhering to the flask wall and media were exchanged every two days. The cells were digested and passaged with $0.25 \%$ trypsin, and cells in the logarithmic growth phase were used for the subsequent experiments.

Methods. The percentage of $\mathrm{CD} 13^{+}$cells in each group was determined by flow cytometry, the expression of HIF-1 $\alpha$ and VEGF were detected by western blot analysis, the cell proliferation rate was detected by the MTT assay and the apoptotic rate was detected by flow cytometry at 12,24 and $72 \mathrm{~h}$ respectively.

Flow cytometric determination of the percentage of $\mathrm{CD} 133^{+}$ and apoptotic cells. Equivalent amounts of cells from each group were resuspended at final concentration of $2 \times 10^{6} / \mathrm{ml}$ and mixed with mouse anti-human monoclonal antibody (1:200; Sigma-Aldrich, St. Louis, MO, USA). The mixtures were incubated for $1 \mathrm{~h}$ at room temperature in the dark and then centrifuged at $2,000 \mathrm{x}$ g for $10 \mathrm{~min}$. The supernatants were discarded. Then, $5 \mathrm{ml}$ phosphate-buffered saline (PBS) (10 mM, pH=7.4) were added and the samples were resuspended, after centrifugation at 2,000 x $\mathrm{g}$ for $10 \mathrm{~min}$, the supernatants were discarded again, $1 \mathrm{ml}$ PBS was added and the samples were resuspended again. The percentages of $\mathrm{CD}_{133^{+}}$cells were determined within $1 \mathrm{~h}$ using a FACSCaliber flow cytometer (BD Biosciences, Franklin Lakes, NJ, USA).

To determine the apoptotic cell percentages equivalent amounts of cells were centrifuged at $1,500 \mathrm{x}$ g for $10 \mathrm{~min}$, the supernatants were discarded and the samples were washed with PBS. After centrifugation at $1,500 \mathrm{x} g$ for $10 \mathrm{~min}$ the precipitates were collected. Binding buffer $(100 \mu \mathrm{l})$ and $10 \mu \mathrm{l}$ of FITC-conjugated Annexin V $(20 \mu \mathrm{g} / \mathrm{ml})$ (both from Jiangsu Biyuntian Technology, Jiangsu, China) were added to each sample and were placed in an incubator for $30 \mathrm{~min}$ at room temperature in the dark. Subsequently, $5 \mu \mathrm{l}$ of PI $(50 \mu \mathrm{g} / \mathrm{ml}$; Jiangsu Biyuntian Technology) were added and the samples were incubated for $5 \mathrm{~min}$ in the dark. Then, $400 \mu \mathrm{l}$ binding buffer were added and the samples were detected within $1 \mathrm{~h}$ by flow cytometry. The cells without Annexin V-FITC and PI were used as negative controls.

Determination of HIF-1 $\alpha$ and VEGF expression levels by western blot analysis. Equivalent amounts of cell culture medium from each batch of cells were centrifuged at 1,500 x g for $10 \mathrm{~min}$ and the supernatants were discarded. The samples were washed with PBS and then centrifuged at 1,500 $\mathrm{x} g$ for $10 \mathrm{~min}, 0.2 \mathrm{~g}$ of cell precipitate were collected and washed with PBS. RIPA lysis buffer (500 $\mu \mathrm{l}$; Jiangsu Biyuntian Technology) was added, each sample was homogenized in a vortex 10 times and then transferred to a centrifuge tube. The centrifuge tube was placed in an ice bath and proteins were allowed to lyse for $30 \mathrm{~min}$, then each sample was centrifuged at $4^{\circ} \mathrm{C}$ at $3,000 \mathrm{x} \mathrm{g}$ for $5 \mathrm{~min}$ and the supernatant was transferred to $1.5 \mathrm{ml}$ centrifuge tubes and stored at $-20^{\circ} \mathrm{C}$.
The BCA assay (Jiangsu Biyuntian Technology) was used to measure protein concentrations and purity. Total protein $(30 \mu \mathrm{g})$ was mixed with $5 \mathrm{X}$ loading buffer. A $10 \%$ separation gel and a $4 \%$ concentration gel were prepared, and the samples were separated by $8 \%$ SDS-PAGE (Invitrogen, Carlsbad, CA, USA). The electrophoresis voltage was set at $80 \mathrm{~V}$ for $30 \mathrm{~min}$ for the concentration gel and $120 \mathrm{~V}$ for $3 \mathrm{~h}$ for the separation gel (until the bromophenol blue reached the bottom of the gel). The separated proteins were transferred to a PVDF membrane (Invitrogen). Mouse monoclonal HIF-1 $\alpha$ antibody (dilution, 1:500; cat. no. ab113642), mouse monoclonal VEGF antibody (dilution, 1:500; cat. no. ab9530) were added and the membranes were incubated overnight at $4^{\circ} \mathrm{C}$, $\beta$-actin was used as internal reference protein for normalizing quantities. Secondary rabbit anti-mouse (HRP) IgG antibody (dilution, 1:2,000; cat. no. ab6728) was added and the membranes were incubated at room temperature for $4 \mathrm{~h}$, then the membranes were washed with PBS, ECL was added onto each membrane and blots were developed in the dark. Images were scanned and stored. The data was semi-quantitatively analyzed with LabWorks 4.5 Image Analysis software (BioRad Laboratories, Inc., Hercules, CA, USA).

Determination of cell proliferation rate by the MTT assay. Cell samples were resuspended to a final concentration of $2 \times 10^{6} / \mathrm{ml}$ and seeded in 96-well plates with $100 \mu \mathrm{l} /$ well. After 12, 24 and $72 \mathrm{~h}, 10 \mu \mathrm{l}$ of $5 \mathrm{mg} / \mathrm{ml}$ MTT (Bio-Rad Laboratories, Inc.) were added into each well. After $4 \mathrm{~h}$, the supernatants were discarded and $150 \mu \mathrm{l}$ of DMSO (Bio-Rad Laboratories, Inc.) were added into each well. The samples were agitated for 10 min and the optical density (OD) at A490 nm was measured in a microplate reader (Bio-Rad Laboratories, Inc.). Samples were measured three times, and the calculated average was used as the result in each case. The cell proliferation rates were calculated according to the following formula: Proliferation rate $(\%)=\mathrm{OD}$ value of the experimental group/OD value of the control group x $100 \%$.

Statistical analysis. Statistical analysis was performed using SPSS 20.0 statistical software (SPSS, Inc., Chicago, IL, USA). Measurement data were expressed as means \pm standard deviation, and the one-way analysis of variance was used to compare the data at different time-points. $\mathrm{P}<0.05$ was considered to indicate a statistically significant difference.

\section{Results}

Comparison of $\mathrm{CD} 33^{+}$cell percentages. The percentage of $\mathrm{CD}_{133}{ }^{+}$cells in the hypoxia group increased gradually from 12 to 24 to $72 \mathrm{~h}$, while there was no change in the control group. The difference at each time-point was significantly higher in the hypoxia group $(\mathrm{p}<0.05)$ (Fig. 1).

Comparison of HIF-1 $\alpha$ and VEGF expression levels. The expression levels of HIF-1 $\alpha$ and VEGF in the hypoxia group were gradually increased from 12 to 24 and to $72 \mathrm{~h}$, while the levels in the control group exhibited no changes. The level in the hypoxia group at each time-point was significantly higher than the corresponding level in the control group $(\mathrm{p}<0.05)$ (Fig. 2). 


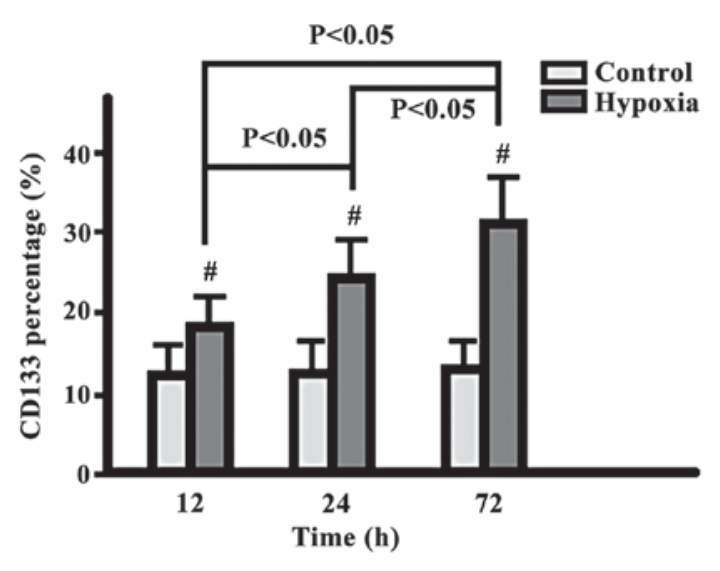

Figure 1. Determination of $\mathrm{CD}_{133^{+}}$cell percentage by flow cytometry. ${ }^{\prime} \mathrm{P}<0.05$, the difference between the hypoxia and control groups at each time-point.
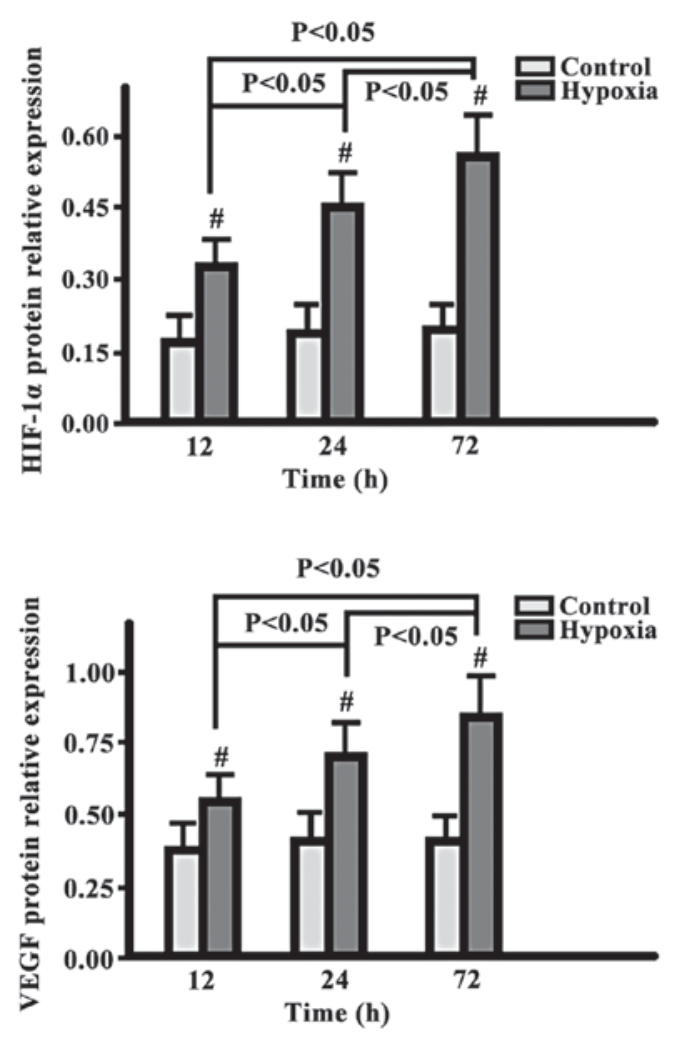

Figure 2. Determination of HIF-1 $\alpha$ and VEGF expression levels by western blot analysis. Difference between the cells in the hypoxia and control groups at each time-point, ${ }^{\#} \mathrm{p}<0.05$. HIF- $1 \alpha$, hypoxia-inducible factor- $1 \alpha$; VEGF, vascular endothelial growth factor.

Comparison of cell proliferation rate. The cell proliferation rates in the two groups increased gradually from 12 to 24 and to $72 \mathrm{~h}$, but the proliferation in the hypoxia group was significantly higher than that in the control group ( $\mathrm{p}<0.05)$ (Fig. 3).

Comparison of cell apoptotic cell percentages. There were no significant changes in terms of the apoptotic cell percentages between the two groups at different time-points, but the percentage in the hypoxia group was significantly lower than that in the control group at each same time-point $(\mathrm{p}<0.05)$ (Fig. 4).

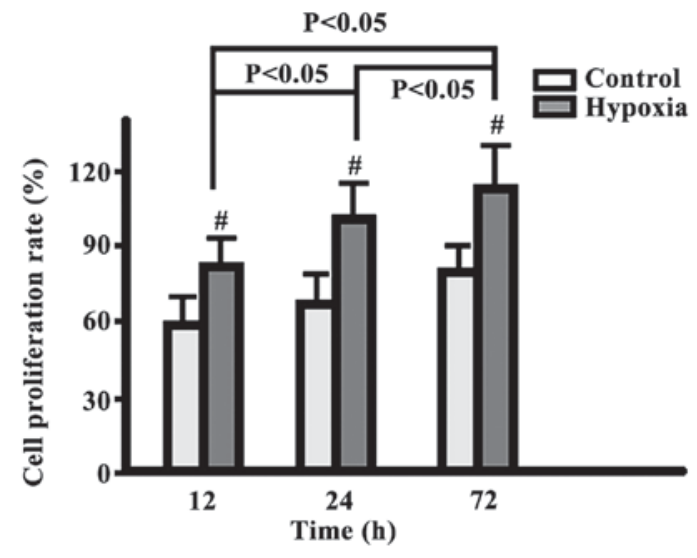

Figure 3. Determination of percentage of proliferating cells using an MTT assay. ${ }^{\#} \mathrm{P}<0.05$, difference between the cells in the hypoxia and control groups at each time-point.

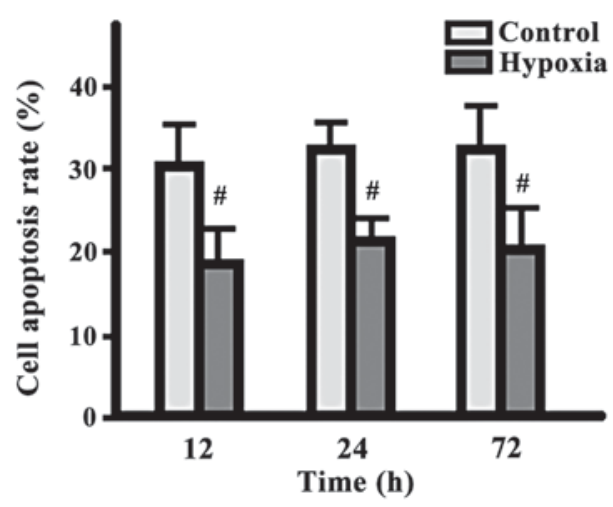

Figure 4. Determination of percentage of apoptotic cells by flow cytometry. ${ }^{\#} \mathrm{P}<0.05$, difference between the cells in the hypoxia and control groups at each time-point.

\section{Discussion}

Tissue hypoxia is an important factor in the occurrence of a variety of diseases, such as cancer, pulmonary vascular remodeling and aging (9). Hypoxia in tumor cells is related to energy metabolism disorders, DNA damage repair, inflammatory response, oxidative stress and apoptosis (10). In this study, our results showed that the percentage of $\mathrm{CD} 133^{+}$cells, and the expression of HIF-1 $\alpha$ and VEGF in the hypoxia group cells increased gradually, while the cells in the control group exhibited no such changes. Moreover, the values for the hypoxia group cells at each time-point were significantly higher than those in the control group cells. The cell proliferation rate increased gradually in the two groups, but the proliferation in the hypoxia group was significantly higher than that in the control group at any time-point. The percentage of apoptotic cells did not change significantly with time in either group, whereas the hypoxia group had less apoptotic cells than the control group at all the time-points.

The results suggest that the expression of CD133+, HIF-1 $\alpha$ and VEGF in human prostate cancer cells is associated with hypoxia. It is known that hypoxic environments can increase the expression of HIF-1 $\alpha$ and VEGF proteins in tumor cells, promote cell proliferation and inhibit cell apoptosis. In fact, 
the hypoxic prostate $\mathrm{LNCaP}$ cancer cell line was transplanted subcutaneously to mice in another study, and the tumor growth rate was significantly faster than that in mice transplanted with normoxic cells (11). Furthermore, immunohistochemical staining of human prostate cancer tissues found that CD133+ cell, HIF-1 $\alpha$ and VEGF expression levels were correlated with tumor clinical stage and differentiation degree, and patients with a high expression of these proteins often showed poor clinical prognosis (12). By contrast, $\mathrm{CD} 133^{+}$were notably absent from normal prostate tissues (13).

The resistance to chemotherapy is increased in $\mathrm{CD}_{133^{+}}$ hepatocellular carcinoma cells, where selective activation of the Akt/PKB and Bcl-2 signaling pathways inhibits cell apoptosis and promotes cell survival (14). CD133+ human prostate cancer cells exhibit a strong proliferative capacity and invasiveness, and may promote angiogenesis by inducing the expression of matrix metalloproteinase (MMP)-9 (15) and VEGF (16). Furthermore, these cells play a role escaping the immune system by association with the MHC class I-related chain A (ADAM9/MHC class I-related chain A, MICA) pathway (17). HIF-1 $\alpha$ is an oxygen-dependent transcriptional activator that induces transcsription of a variety of downstream target genes by binding to the hypoxia response element (HRE) (18). HIF-1 $\alpha$ is highly expressed in a variety of tumor tissues, and the VEGF gene promoter contains the HIF-1 $\alpha$ binding sequence (18). The hypoxiainduced expression of HIF-1 $\alpha$ is transient, and iron-ion chelating agents binding to iron ions on HIF-1 $\alpha$ can inhibit the degradation of HIF-1 $\alpha$ (19). However, simply increasing the oxygen concentration in tissues does not lead to inhibition of cell proliferation, cell apoptosis promotion or a reduction in $\mathrm{CD}_{133^{+}}$cells, suggesting that hypoxia stimulation is the determinant factor (20). Nevertheless, inhibiting the expression of $\mathrm{CD} 133^{+}$, HIF-1 $\alpha$ and VEGF is a potential strategy for interfering with tumors. As an example of this approach, a study by Liu et al (21) confirmed that the compound berberine inhibited HIF-1 $\alpha$ and VEGF expression activity in tumor cells, resulting in tumor proliferation inhibition.

In conclusion, the present study proved that hypoxia can induce the expression of CD133 $3^{+}$, HIF- $1 \alpha$ and VEGF in prostate cancer cells and thereby regulate cell proliferation and apoptosis. A treatment to alter the expressions of $\mathrm{CD}_{133^{+}}$, HIF-1 $\alpha$ and VEGF may be a successful approach to prevent and cure prostate cancer.

\section{References}

1. He F, Fang Z, Shen C and Li L: Meta-analysis of the effect of postoperative radiotherapy on prognosis of prostatic cancer following radical prostatectomy. Int J Clin Exp Med 8: 20589-20595, 2015.

2. Zhang Q, Zhang C, Yang X, Yang B, Wang J, Kang Y, Wang Z, Li D, Huang G, Ma Z, et al: Berberine inhibits the expression of hypoxia induction factor-1alpha and increases the radiosensitivity of prostate cancer. Diagn Pathol 9: 98, 2014.

3. Mimeault M and Batra SK: Hypoxia-inducing factors as master regulators of stemness properties and altered metabolism of cancer- and metastasis-initiating cells. J Cell Mol Med 17: $30-54,2013$
4. Bao B, Ahmad A, Kong D, Ali S, Azmi AS, Li Y, Banerjee S, Padhye $S$ and Sarkar FH: Hypoxia induced aggressiveness of prostate cancer cells is linked with deregulated expression of VEGF, IL-6 and miRNAs that are attenuated by CDF. PLoS One 7: e43726, 2012.

5. Kitajima Y and Miyazaki K: The critical impact of HIF-1a on gastric cancer biology. Cancers (Basel) 5: 15-26, 2013.

6. Liu F, Qi CL, Kong M, Liu TT, Li L and Li BJ: Screening specific polypeptides of breast cancer stem cells from a phage display random peptide library. Oncol Lett 12: 4727-4731, 2016.

7. Jaworska D, Król W and Szliszka E: Prostate cancer stem cells: Research advances. Int J Mol Sci 16: 27433-27449, 2015.

8. Bayin NS, Modrek AS, Dietrich A, Lebowitz J, Abel T, Song HR, Schober M, Zagzag D, Buchholz CJ, Chao MV, et al: Selective lentiviral gene delivery to CD133-expressing human glioblastoma stem cells. PLoS One 9: e116114, 2014.

9. Labrecque MP, Takhar MK, Nason R, Santacruz S, Tam KJ, Massah S, Haegert A, Bell RH, Altamirano-Dimas M, Collins CC, et al: The retinoblastoma protein regulates hypoxia-inducible genetic programs, tumor cell invasiveness and neuroendocrine differentiation in prostate cancer cells. Oncotarget 7: 24284-24302, 2016.

10. Wu M, Wang X, McGregor N, Pienta KJ and Zhang J: Dynamic regulation of Rad51 by E2F1 and p53 in prostate cancer cells upon drug-induced DNA damage under hypoxia. Mol Pharmacol 85: 866-876, 2014

11. Deep G and Panigrahi GK: Hypoxia-induced signaling promotes prostate cancer progression: Exosomes role as messenger of hypoxic response in tumor microenvironment. Crit Rev Oncog 20: 419-434, 2015.

12. Pellacani D, Packer RJ, Frame FM, Oldridge EE, Berry PA, Labarthe MC, Stower MJ, Simms MS, Collins AT and Maitland NJ: Regulation of the stem cell marker CD133 is independent of promoter hypermethylation in human epithelial differentiation and cancer. Mol Cancer 10: 94, 2011.

13. Dey P, Velazquez-Villegas LA, Faria M, Turner A, Jonsson P, Webb P, Williams C, Gustafsson JA and Ström AM: Estrogen receptor $\beta 2$ induces hypoxia signature of gene expression by stabilizing HIF- $1 \alpha$ in prostate cancer. PLoS One 10: e0128239, 2015.

14. Chen H, Luo Z, Dong L, Tan Y, Yang J, Feng G, Wu M, Li Z and Wang H: CD133/prominin-1-mediated autophagy and glucose uptake beneficial for hepatoma cell survival. PLoS One 8: e56878, 2013

15. Mak AB, Schnegg C, Lai CY, Ghosh S, Yang MH, Moffat J and Hsu MY: CD133-targeted niche-dependent therapy in cancer: A multipronged approach. Am J Pathol 184: 1256-1262, 2014.

16. Zhou J, Wang H, Cannon V, Wolcott KM, Song H and Yates C: Side population rather than CD133(+) cells distinguishes enriched tumorigenicity in hTERT-immortalized primary prostate cancer cells. Mol Cancer 10: 112, 2011.

17. Reyes EE, Gillard M, Duggan R, Wroblewski K, Kregel S, Isikbay M, Kach J, Brechka H, Weele DJ, Szmulewitz RZ, et al: Molecular analysis of CD133-positive circulating tumor cells from patients with metastatic castration-resistant prostate cancer. J Transl Sci 1: 2015. doi: 10.15761/JTS.1000104.

18. Park JJ, Jin YB, Lee YJ, Lee JS, Lee YS, Ko YG and Lee M: KAI1 suppresses HIF-1 $\alpha$ and VEGF expression by blocking CDCP1-enhanced Src activation in prostate cancer. BMC Cancer 12: 81, 2012.

19. Huang H, Benzonana LL, Zhao H, Watts HR, Perry NJ, Bevan C, Brown R and Ma D: Prostate cancer cell malignancy via modulation of HIF-1 $\alpha$ pathway with isoflurane and propofol alone and in combination. Br J Cancer 111: 1338-1349, 2014.

20. Lee SO, Kim JS, Lee MS and Lee HJ: Anti-cancer effect of pristimerin by inhibition of HIF- $1 \alpha$ involves the SPHK-1 pathway in hypoxic prostate cancer cells. BMC Cancer 16: $701,2016$.

21. Liu CH, Tang WC, Sia P, Huang CC, Yang PM, Wu MH, Lai IL and Lee KH: Berberine inhibits the metastatic ability of prostate cancer cells by suppressing epithelial-to-mesenchymal transition (EMT)-associated genes with predictive and prognostic relevance. Int J Med Sci 12: 63-71, 2015. 